\title{
Bronchial Asthma Developing after 15 Years of Immunosuppressive Treatment Following Renal Transplantation
}

\author{
Hidehiro Watanabe, Tomonori Uruma, Tokuro Tsunoda, \\ Hiroshi Ishii, Gen Tazaki and Tetsuri Kondo
}

\begin{abstract}
A 42-year-old woman who underwent renal transplantation from her mother at the age of 26 due to $\operatorname{IgA}$ nephropathy had since been treated with immunosuppressive agents, including prednisolone (PSL), azathioprine (AZA) and cyclosporine (CsA). The patient had remained clinically stable for 15 years. However, in the middle of May 2010, she developed bronchial asthma for the first time after performing house-cleaning activities and was treated with corticosteroids and antiasthmatic agents. The use of immunosuppressive agents as a treatment for severe bronchial asthma might have been related to the manifestation of bronchial asthma in this case.
\end{abstract}

Key words: bronchial asthma, immunosuppressive treatment, renal transplantation

(Intern Med 51: 3057-3060, 2012)

(DOI: 10.2169/internalmedicine.51.7575)

\section{Introduction}

The standard treatment for bronchial asthma based on the use of anti-inflammatory agents such as inhaled corticosteroids (ICS) and leukotriene receptor antagonists (LTRA) has become widespread. The reduction in the bronchial-asthma death rate observed in Japan from roughly 6,000 patients/ year in the 1990 s to 2,065 patients/year in 2010 is considered to have resulted from the use of this standard treatment (1). Recently, the frequency of exacerbation and the need for urgent consultation in patients with moderate to severe bronchial asthma have also significantly decreased due to the use of anti-IgE antibody (omalizumab) treatment $(2,3)$. Moreover, both the efficacy and safety of longterm therapy with omalizumab have been reported (4). On the other hand, since the 1990s, various immunosuppressive medicines, including methotrexate (5), azathioprine (AZA) (6), cyclosporine (CsA) $(7,8)$ and troleadomycin (9) have been applied to treat steroid-dependent severe bronchial asthma in order to reduce the use of systemic corticosteroids. These immunosuppressive medicines are thought to inhibit $\mathrm{T}$ cell activation in the chronic airway inflammation that occurs in bronchial asthma $(10,11)$. The current patient had received immunosuppressive therapy, including CsA and AZA, for 15 years due to undergoing renal transplantation. The activation of $\mathrm{T}$ cells must therefore have been inhibited in this case. It is considered rare that bronchial asthma developed in an individual receiving this treatment.

\section{Case Report}

The patient was a 42-year-old Japanese woman with a past history of renal transplantation from her mother due to IgA nephropathy at 26 years of age that was performed at another hospital. After undergoing organ transplantation, the patient began to receive prednisolone (PSL), AZA and CsA as immunosuppressive therapy. After her clinical symptoms became satisfactory, the dose of PSL was reduced and ultimately discontinued by 2007. Thereafter, the patient was prescribed AZA (75 mg/day) and CsA (100 mg/day) as immunosuppressive therapy and was free from clinical symptoms until 2010. Regarding her lifestyle, the patient had no 
Table 1. Laboratory Data on Admission

\begin{tabular}{|c|c|c|c|c|}
\hline \multicolumn{2}{|l|}{ Hematology } & \multicolumn{3}{|l|}{ Biochemistry } \\
\hline WBC & 7,600 & $\mathrm{Na}$ & 142 & $\mathrm{mEq} / \mathrm{L}$ \\
\hline Seg & 97.0 & $\mathrm{~K}$ & 4.7 & $\mathrm{mEq} / \mathrm{L}$ \\
\hline Eosino & 0.0 & $\mathrm{Ca}$ & 9.6 & $\mathrm{mEq} / \mathrm{L}$ \\
\hline Mono & 1.0 & BUN & 24 & $\mathrm{mg} / \mathrm{dL}$ \\
\hline Lymp & 2.0 & $\mathrm{Cr}$ & 1.43 & $\mathrm{mg} / \mathrm{dL}$ \\
\hline $\mathrm{RBC}$ & $\times 10^{4} / \mu \mathrm{L}$ & $\mathrm{TP}$ & 8.0 & $\mathrm{~g} / \mathrm{dL}$ \\
\hline $\mathrm{Hb}$ & $\mathrm{g} / \mathrm{dL}$ & T-Bil & 0.6 & $\mathrm{mg} / \mathrm{dL}$ \\
\hline $\mathrm{Ht}$ & 31.2 & ALP & 220 & IU/L \\
\hline \multirow[t]{2}{*}{ Plt } & $\times 10^{4} / \mu \mathrm{L}$ & $\gamma$-GTP & 10 & $\mathrm{IU} / \mathrm{L}$ \\
\hline & & AST & 16 & $\mathrm{IU} / \mathrm{L}$ \\
\hline Sputum & & ALT & 8 & $\mathrm{IU} / \mathrm{L}$ \\
\hline Eosino & $40 \%$ & $\mathrm{LDH}$ & 167 & $\mathrm{IU} / \mathrm{L}$ \\
\hline \multirow[t]{2}{*}{ Culture } & Normal Flora & Glu & 124 & $\mathrm{mg} / \mathrm{dL}$ \\
\hline & & CRP & 0.14 & $\mathrm{mg} / \mathrm{dL}$ \\
\hline Allergy MAST & Score & & & \\
\hline House dust & 0 & Immunology & & \\
\hline Mites & 0 & $\operatorname{IgG}$ & 1,028 & $\mathrm{mg} / \mathrm{mL}$ \\
\hline Japanese cedar & 3 & $\operatorname{Ig} \mathrm{A}$ & 213 & $\mathrm{mg} / \mathrm{mL}$ \\
\hline Vernal grass & 2 & $\operatorname{IgM}$ & 199 & $\mathrm{mg} / \mathrm{mL}$ \\
\hline Penicillium & 1 & $\mathrm{IgE}$ & 235 & $\mathrm{IU} / \mathrm{mL}$ \\
\hline Candida & 1 & & & \\
\hline Dog epithelium & 2 & CsA conc.(Trough) & 45 & $\mathrm{ng} / \mathrm{mL}$ \\
\hline Cat epithelium & 1 & & & \\
\hline
\end{tabular}

past history of allergic disease, including bronchial asthma, and did not smoke or drink alcohol. She kept a dog as a pet in her home from 1997 to the present. She had no fraternal relatives and her parents also had no past history of bronchial asthma.

The patient began experiencing coughing and dyspnea after performing house-cleaning activities at the end of May 2010 and consulted a physician. At that time, she was prescribed a cough remedy, an expectorant and an inhaled corticosteroid due to a diagnosis of allergic bronchitis. However, she was admitted to our hospital on June due to aggravated symptoms. On the day of admission, the patient had dyspnea and her oxygen saturation was $96 \%$ under one liter of oxygen inhalation. The patient's body temperature was $37.0^{\circ} \mathrm{C}$ and there was no evidence of swollen lymph nodes, eczema or other abnormalities, except for audible wheezing. The patient's white blood cell (WBC) count was $7,600 / \mu \mathrm{L}$ and the percentage of neutrophils and eosinophils was $97 \%$ and $0 \%$, respectively. A slight renal dysfunction was noted (BUN: $24 \mathrm{mg} / \mathrm{dL}$; Cr: $1.48 \mathrm{mg} / \mathrm{dL}$ ) and the CRP level was $0.4 \mathrm{mg} / \mathrm{dL}$. However, the ratio of eosinophils in the sputum displayed a significantly high value $(40 \%)$ and the immunoglobulin E (IgE) level was $234 \mathrm{IU} / \mathrm{mL}$. On multiple antigen simultaneous tests (MAST), high scores were obtained for Japanese cedar, vernal grass and dog epithelium (Table 1). A reduction was observed on lung function tests regarding the rate of forced expiratory volume in one second (FEV1) to forced vital capacity (FVC): $57.9 \%$. In addition, an improvement of $190 \mathrm{cc}$ in FEV1 was observed after the administration of procaterol inhalation ( $20 \mu \mathrm{g} / 2 \mathrm{puff})$, and an improvement rate of $10.9 \%$ was observed during a bronchodilator loading lung function test (Table 2). Although only slight hyperinflation was observed on chest X-rays, no bronchiolitis obliterans was observed on computed tomography (Figure). At that time, the trough concentration of cyclosporine was $45 \mathrm{ng} / \mathrm{mL}$ with a maintenance of the lower limit of the effective concentration.

At that point, the patient was diagnosed with bronchial asthma for the first time. After admission, she was immediately treated with inhaled salmeterol/fluticasone propionate $(50 / 250 \mu \mathrm{g}$ bid), an oral leukotriene antagonist (pranlukast hydrate: $450 \mathrm{mg} /$ day) and an intravenous drip infusion of methylprednisolone (120 mg/day) and theophylline $(500 \mathrm{mg} /$ day). The patient's symptoms improved markedly after these treatments. In particular, both the dyspnea and wheezing disappeared and oxygen inhalation became unnecessary after several days. After one week, the patient was discharged with no complaints. One month after discharge, her respiratory function had recovered normally (Table 2). The patient's symptoms were stabilized with only ICS, and the eosinophils in the sputum also disappeared. The finding of slight hyperinflation on chest X-rays improved and no asthmatic attacks have occurred since discharge.

\section{Discussion}

Cyclosporine exerts immunosuppressive and antiinflammatory actions by inhibiting activated $\mathrm{T}$ cells as its primary mode of efficacy in steroid-dependent bronchial asthma $(10,11)$. In addition, it plays an important role, not only in the suppression of organ transplantation rejection (12), but also in the treatment of autoimmune diseases (13). Cyclosporine as a prodrug becomes active when it forms a complex with the intracellular receptor cyclophilin, which acts as a binding protein. The resulting cyclosporine-cyclophilin complex prevents the translocation of the cytoplasmic component of the nuclear factor of activated $\mathrm{T}$ cells (NF-AT) to the nucleus via the suppression of calcineurin, thereby inhibiting the subsequent activation of the genes encoding cytokines (14). Since this cytoplasmic pathway differs from the mechanism of action of corticosteroids, cyclosporine is considered to display an efficacy in the treatment of steroid-dependent bronchial asthma $(7,8)$. However, there are some reports that the suppression of interleukin (IL)-4 and IL-5 in the Th2 system by CsA is weaker than that of corticosteroids (15). In addition, CsA is considered to primarily control interferon- $\gamma$ and IL-2 in the Th1 system, while also acting to prevent foreign body rejection (16). On the other hand, regarding the relationship between organ transplantation and $\mathrm{IgE}$, some reports have indicated that IgE allergies do not improve by CsA in pediatric patients undergoing renal transplantation (17) and in lung transplant recipients (18). Moreover, there is a report that bronchial asthma occurred in three of 50 pediatric liver transplant recipients under systemic treatment with tacrolimus and CsA (19). In this case, it was thought that the early phase rejection of renal transplantation had been 
Table 2. The Findings of the Lung Function Tests during the Patient's Clinical Course

\begin{tabular}{llrrrr}
\hline \multirow{2}{*}{$\begin{array}{l}\text { Lung function } \\
\end{array}$} & \multicolumn{2}{c}{$\begin{array}{c}6.2010 \\
\text { Pre-Procaterol }\end{array}$} & Post-Procaterol & 7.2010 & 9.2010 \\
\hline FVC & $(\mathrm{L})$ & 3.18 & 3.21 & 3.56 & 3.48 \\
$\mathrm{FEV}_{1}$ & $(\mathrm{~L})$ & 1.84 & 2.03 & 2.78 & 2.65 \\
$\mathrm{FEV}_{1} / \mathrm{FVC}$ & $(\%)$ & 57.9 & 63.2 & 78.1 & 76.1 \\
$\mathrm{FEV}_{1} \%$ predicted & $(\%)$ & 64.8 & 71.5 & 97.9 & 93.3 \\
$\dot{\mathrm{V} 50}$ & $(\mathrm{~L} /$ second $)$ & 1.00 & 1.52 & 2.72 & 2.45 \\
$\dot{\mathrm{V}} 25$ & $(\mathrm{~L} /$ second $)$ & 0.32 & 0,52 & 1.11 & 1.22 \\
\hline
\end{tabular}

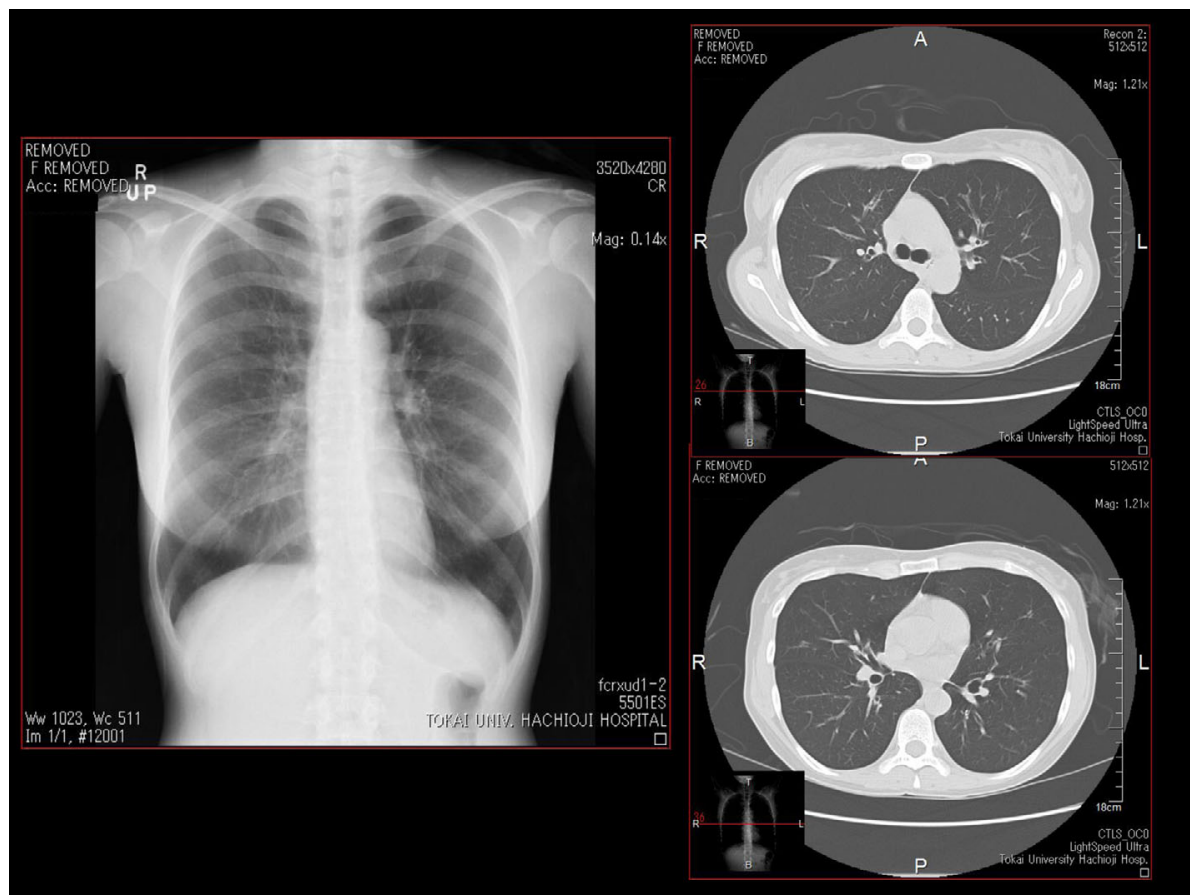

Figure. Chest $\mathrm{X}$-ray and computed tomography on admission. Slight hyperinflation and a pendulous heart were observed.

controlled by immunosuppressive agents, including PSL, CsA and AZA. These immunosuppressive agents suppress and maintain a balance between Th1 and Th2 systemic cytokines. In particular, it is thought that CsA and AZA primarily control the response of the Th1 system (16), while PSL controls that of the Th2 system. In this case, the blood concentration of CsA was maintained at the lower limit of its effective concentration. On the other hand, it seems that this patient had an atopic factor because the MAST was positive for Japanese cedar, Penicillium, dog epithelium and cat epithelium. It is thought that the atopic factor was also controlled by the immunosuppressive treatment. Therefore, no rejection or allergic reactions occurred, including bronchial asthma, in this case for 15 years. Indeed, in this patient, the percentage of eosinophils in the WBC was maintained at less than $4 \%$ until 2007. However, the percentage of eosinophils gradually increased after the termination of PSL in 2007. This percentage was 5.5\% (WBC: $5,900 / \mu \mathrm{L}$ ) in October 2008 and 10.3\% (WBC: 7,200/ $\mu \mathrm{L}$ ) in April 2009. These findings suggest that the suppression of Th2 systemic cytokines decreased due to the termination of PSL.
As a result, a relative $\mathrm{Th} 2$ dominance resulted and a Th2 systemic response to a unique antigen occurred. Furthermore, it is surmised that the first incidence of bronchial asthma was induced by an $\operatorname{IgE}$ response that occurred due to massive antigen exposure to substances, such as dog epithelium, after house-cleaning activities.

In summary, this report of a case of bronchial asthma that developed after 15 years of immunosuppressive treatment due to renal transplantation suggests that immunosuppressive agents do not improve IgE allergies, although these agents do exert a depressive effect on the Th1 system.

The authors state that they have no Conflict of Interest (COI).

\section{References}

1. [Annual population survey report from the Ministry of Health, Labour and Welfare of Japan 2010] (in Japanese). Available at: http://www.mhlw.go.jp/toukei/saikin/hw/jinkou/kakutei10/dl/11_h7. pdf

2. Humbert M, Beasley R, Ayres J, et al. Benefits of omalizumab as 
add-on therapy in patients with severe persistent asthma who are inadequately controlled despite best available therapy (GINA 2002 step 4 treatment): INNOVATE. Allergy 60: 309-316, 2005.

3. Busse W, Corren J, Lanier BQ, et al. Omalizumab, anti-IgE recombinant humanized monoclonal antibody, for the treatment of severe allergic asthma. J Allergy Clin Immunol 108: 184-190, 2001.

4. Ohta K, Yamamoto M, Sato N, Ikeda K, Miyamoto T. One year treatment with omalizumab is effective and well tolerated in Japanese patients with moderate-to-severe persistent asthma. Allergol Int 59: 167-174, 2010.

5. Comet R, Domingo C, Larrosa M, et al. Benefits of low weekly doses of methotrexate in steroid-dependent asthmatic patients. A double-blind, randomized, placebo-controlled study. Respir Med 100: 411-419, 2006.

6. Hodges NG, Brewis RA, Howell JB. An evaluation of azathioprine in severe chronic asthma. Thorax 26: 734-739, 1971.

7. Nizankowska E, Soja J, Pinis G, et al. Treatment of steroiddependent bronchial asthma with cyclosporin. Eur Respir J 8: 1091-1099, 1995.

8. Lock SH, Kay AB, Barnes NC. Double-blind, placebo-controlled study of cyclosporin $\mathrm{A}$ as a corticosteroid-sparing agent in corticosteroid-dependent asthma. Am J Respir Crit Care Med 153: 509-514, 1996.

9. Kamada AK, Hill MR, Iklé DN, Brenner AM, Szefler SJ. Efficacy and safety of low-dose troleandomycin therapy in children with severe, steroid-requiring asthma. J Allergy Clin Immunol 91: 873882, 1993.

10. Fukuda T, Asakawa J, Motojima S, Makino S. Cyclosporine A reduces $\mathrm{T}$ lymphocyte activity and improves airway hyperresponsiveness in corticosteroid-dependent chronic severe asthma. Ann
Allergy Asthma Immunol 75: 65-72, 1995.

11. Alexander AG, Barnes NC, Kay AB. Trial of cyclosporin in corticosteroid-dependent chronic severe asthma. Lancet 339: 324328, 1992.

12. Colombo D, Ammirati E. Cyclosporine in transplantation: a history of converging timelines. J Biol Regul Homeost Agents 25: 493-504, 2011.

13. Ogawa $H$, Kameda H, Amano K, Takeuchi T. Efficacy and safety of cyclosporine $\mathrm{A}$ in patients with refractory systemic lupus erythematosus in a daily clinical practice. Lupus 19: 162-169, 2010.

14. Sigal NH, Dumont FJ. Cyclosporin A, FK-506, and rapamycin: pharmacologic probes of lymphocyte signal transduction. Annu Rev Immunol 10: 519-560, 1992.

15. Schmidt J, Fleissner S, Heimann-Weitschat I, Lindstaedt R, Szelenyi I. The effect of different corticosteroids and cyclosporin A on interleukin-4 and interleukin-5 release from murine TH2type T cells. Eur J Pharmacol 260: 247-250, 1994.

16. van den Berg AP, Twilhaar WN, Corver K, et al. Cyclosporine A is associated with a shift of the Th1/Th2 balance in liver transplant patients. Transplant Proc 30: 2378-2379, 1998.

17. Kawamura N, Furuta H, Tame A, et al. Extremely high serum level of IgE during immunosuppressive therapy: paradoxical effect of cyclosporine A and tacrolimus. Int Arch Allergy Immunol 112: 422-424, 1997.

18. Gruber S, Dehlink E, Eiwegger $T$, et al. Immunoglobulin emediated allergies in lung-transplanted adults. Transplantation 84: 275-279, 2007.

19. Arikan C, Kilic M, Tokat $Y$, Aydogdu S. Allergic disease after pediatric liver transplantation with systemic tacrolimus and cyclosporine a therapy. Transplant Proc 35: 3039-3041, 2003.

(C) 2012 The Japanese Society of Internal Medicine http://www.naika.or.jp/imonline/index.html 